\title{
Deteksi Mahasiswa Yang Dapat Menyusun Tugas Akhir dengan Metode Visekriterijumsko Kompromisno Rangiranje (VIKOR)
}

\author{
Detection of Students Who Can Compose Final Projects with the Visekriterijumsko \\ Kompromisno Rangiranje (VIKOR) Method
}

\author{
Ramen Antonov Purba ${ }^{1}$, Ambiyar ${ }^{2}$, Unung Verawardina ${ }^{3}$ \\ ${ }^{1}$ Program Studi Manajemen Informatika, Politeknik Unggul LP3M \\ ${ }^{2}$ Fakultas Teknik, Universitas Negeri Padang \\ ${ }^{3}$ Fakultas Pendidikan MIPATEK, IKIP PGRI Pontianak \\ E-mail: ${ }^{1}$ ramenantonovpurba@gmail.com, ambiyar@ft.unp.ac.id, \\ unungverawardina@gmail.com
}

\begin{abstract}
Abstrak
Tugas Akhir merupakan karya yang wajib disusun mahasiswa. Setiap Perguruan Tinggi mengharuskan mahasiswanya menyusun Tugas Akhir sebagai syarat menyelesaikan studi. Setiap Perguruan Tinggi memiliki persyaratan wajib yang harus dipenuhi. Pengamatan dan wawancara langsung yang dilakukan didapatkan banyak mahasiswa tidak dapat melakukan penyusunan Tugas Akhir karena syarat wajib tidak terpenuhi. Disebabkan karena bidang akademik tidak melakukan deteksi di awal terhadap permasalahan yang ada pada mahasiswa. Kecanggihan teknologi informasi berbasis komputerisasi dapat dijadikan solusi permasalahan. Syarat wajib yang ditetapkan Perguruan Tinggi dapat dijadikan sebagai kriteria guna mendeteksi mahasiswa. Metode Metode Visekriterijumsko Kompromisno Rangiranje (VIKOR) yang dapat melakukan proses dengan lebih dari satu kriteria dengan banyak alternatif dapat dipergunakan sebagai solusi. Tujuan penelitian ini untuk mendeteksi mahasiswa yang dapat menyusun Tugas Akhir dengan menggunakan metode VIKOR. Berdasarkan tahapan-tahapan yang dilakukan, akan dibangun dan dihasilkan sistem yang dapat melakukan deteksi dengan cepat. Berdasarkan hasil uji sistem didapatkan nilai rerata 187,40, dimana aplikasi Layak untuk dipergunakan. Nilai ini berasal dari Aspek tampilan 40,56. Aspek Urutan Penggunaan 46,87. Aspek Kecepatan Proses 51,46. Aspek kesesuaian hasil 48.5. Adapun bahasa pemrograman yang dipergunakan untuk membangun sistem yaitu bahasa pemrograman berbasis web dalam hal ini PHP.
\end{abstract}

Kata kunci: Deteksi Awal, Tugas Akhir, VIKOR, Web

\begin{abstract}
The final project is a work that students must compile. Each College requires students to prepare a Final Project as a condition of completing the study. Each College has mandatory requirements that must be met. Observations and direct interviews found that many students could not compile their final assignments because the mandatory requirements were not fulfilled. Because the academic field does not make early detection of problems that exist in students. The sophistication of computerized information technology can be used as a solution to problems. The mandatory requirements set by Higher Education can be used as a criterion for detecting students. The Visekriterijumsko Kompromisno Rangiranje (VIKOR) method, which can perform processes with more than one criterion with many alternatives, can be used as a solution. This study aims to detect students who can compile a final project using the VIKOR method. Based on the steps taken, a system that can detect it will be built and produced quickly. Based on the system test results, the mean value is 187.40, where the application is feasible to use. This value is derived from the Display aspect 40.56. Sequence Aspects of Use 46.87. Process Speed Aspects 51.46. Aspects of conformity of results 48.5. The programming language used to build the system is a web-based programming language, in this case, PHP.
\end{abstract}

Keywords: Early Detection, Final Project, VIKOR, Web 


\section{PENDAHULUAN}

Tugas Akhir merupakan karya yang wajib disusun oleh mahasiswa ketika ingin menyelesaikan studi. Tugas Akhir disusun berdasarkan permasalahan yang ditemukan ketika mahasiswa melakukan Praktek Kerja Lapangan maupun pengamatan langsung ke sebuah objek sesuai dengan peminatannya [1]. Dalam menyusun Tugas Akhir agar hasilnya baik, mahasiswa akan dibimbing dan diarahkan oleh seorang dosen pembimbing. Hampir seluruh Perguruan Tinggi yang ada di Indonesia mengharuskan mahasiswanya untuk menyusun Tugas Akhir sebagai syarat untuk menyelesaikan studi. Perguruan Tinggi tersebut pastinya memiliki persyaratan wajib yang harus dipenuhi agar diizinkan untuk menyusun Tugas Akhir dan mendapatkan penugasan dosen pembimbing.

Pengamatan dan wawancara langsung yang dilakukan dengan Wakil Direktur 1 salah satu Perguruan Tinggi Swasta, didapatkan data yang mengejutkan. Tingkat drop out (DO) mahasiswa sangat tinggi. Banyak mahasiswa yang tidak dapat melakukan penyusunan Tugas Akhir karena syarat wajib tidak terpenuhi. Hal ini disebabkan karena bidang akademik tidak melakukan deteksi di awal terhadap permasalahan yang ada pada mahasiswa. Sebagai contoh Perguruan Tinggi menetapkan 8 (Delapan) syarat wajib agar dapat diberikan ijin untuk menyusun Tugas Akhir. Adapun syarat tersebut yaitu Lulus Mata Kuliah 80 SKS, Lulus 7 Sertifikasi Internal, Lulus 3 Sertifikasi BNSP, Selesai PKL, Lunas Uang Kuliah, dan Selesai Proyek Minor. Ada mahasiswa yang telah lulus mata kuliah 80 SKS, Lulus 7 Sertifikasi Internal, tetapi belum lulus 3 sertifikasi BNSP. Ada mahasiswa yang lulus mata kuliah 80 SKS, lulus 7 sertifikasi internal, lulus 3 sertifikasi BNSP, tetapi belum selesai proyek minor. Permasalahan ini harus diselesaikan. Kecanggihan teknologi informasi berbasis komputerisasi dapat dijadikan solusi permasalahan [2][3]. Syarat wajib yang ditetapkan dapat dijadikan sebagai kriteria guna mendeteksi mahasiswa. Metode Visekriterijumsko Kompromisno Rangiranje (VIKOR) yang dapat melakukan proses dengan lebih dari satu kriteria dengan banyak alternatif dapat dipergunakan sebagai solusi [4].

Mesran, Kurnia Ulfa, Dito Putro Utomo, dan Ida Rizky Nasution dalam penelitiannya menggunakan metode VIKOR untuk melakukan deteksi Air Conditioner (AC) terbaik [5]. Dalam penelitian ini dilakukan perangkingan melalui proses pemanfaatan sistem untuk mendapatkan keputusan. Ada enam (6) kriteria yang dijadikan sebagai parameter, seperti Harga, Quick Cooling (Kecepatan Dingin), Pemakaian Daya Listrik (Watt), Garansi, BTU/h, dan Berat $\mathrm{AC}+$ Kompressor $(\mathrm{kg})$. Penelitian ini menunjukkan metode VIKOR dapat diterapkan dengan baik dalam proses pengambilan keputusan untuk mendeteksi Air Conditioner (AC) terbaik.

Tia Imandasari dan Agus Perdana Windarto menggunakan metode VIKOR dalam penelitian mereka untuk memilih popok bayi berdasarkan jenis kulit [6]. Ada enam (6) kriteria yang dipergunakan, antara lain daya serap, bahan, jenis kulit, cara penggunaan, cara memperoleh, dan harga. Setiap kriteria memiliki bobot yang telah ditetapkan. Penelitian ini menghasilkan kesimpulan bahwa metode VIKOR dapat dipergunakan dalam memilih popok bayi berdasarkan jenis kulit. Dikatakan pula dalam penelitian bahwa metode VIKOR dapat menghasilkan keputusan yang baik berdasarkan pemeringkatan alternative kompromi dari sejumlah alternatif yang ada.

Penelitian yang dilakukan Salvius Paulus Lengkong, Adhistya Erna Permanasari, dan Silmi Fauziati menggunakan metode VIKOR dalam menentukan penerima beasiswa [7]. Penelitian ini menghasilkan bahwa metode VIKOR lebih ideal dalam menghasilkan keputusan. Salvius Paulus Lengkong, Adhistya Erna Permanasari, dan Silmi Fauziati menggunakan metode VIKOR karena kemampuan perangkingan dan dapat melakukan kompromi terhadap alternatif yang ada. Adapun yang menjadi kriteria dalam penelitian tersebut yakni IP Semester, daya listrik, dan tagihan listrik rumah. Dari penelitian yang mereka lakukan terbukti bahwa metode VIKOR lebih mendekati hasil ideal. Penelitian menghasilkan sistem berbasis komputerisasi yang menggabungkan kecanggihan teknologi informasi berbasis komputerisasi dengan metode VIKOR. 
Yogi Primadasa dan Hengky Juliansa dalam penelitiannya menggunakan metode VIKOR dalam melakukan seleksi terhadap salesman yang berhak untuk memperoleh bonus [8]. Ada 4 (empat) yang menjadi kriteria, yaitu Absensi, Pencapaian Target, Kerja Sama Tim dan Perilaku. Yogi Primadasa dan Hengky Juliansa memaparkan bahwa metode VIKOR mampu menghasilkan nilai normalisasi untuk setiap kriteria. Dengan menggunakan metode VIKOR dapat diperoleh salesman yang berhak untuk mendapatkan bonus dengan cepat dan hasilnya akurat. Metode VIKOR dapat menjadi solusi atas permasalahan yang selama ini dialami oleh perusahaan dalam menentukan salesman yang akan menerima bonus. Perusahaan sangat terbantu dengan adanya sistem yang baru.

Dodi Siregar, Heri Nurdiyanto dkk menggunakan metode VIKOR dengan simulasi untuk membuktikan bahwa metode VIKOR dapat dijadikan solusi untuk berbagai masalah pengambilan keputusan [9]. Dikatakan dalam penelitian yang menyebabkan metode VIKOR dapat dijadikan sebagai solusi karena metode VIKOR konsepnya lugas dan mudah untuk dipahami. Proses komputasi dengan menggunakan metode VIKOR juga sangat efisien dalam melakukan pengukuran kinerja berdasarkan alternatif keputusan yang telah ditetapkan. Kesimpulan ini didapatkan setelah dilakukan tahapan proses komputasi berdasarkan hasil eksperimen.

Penelitian ini merupakan pengembangan dari penelitian yang telah ada sebelumnya. Dimana penelitian ini untuk mendeteksi mahasiswa yang dapat menyusun Tugas Akhir dengan menggunakan metode VIKOR. Berdasarkan tahapan-tahapan yang dilakukan, akan dibangun dan dihasilkan sistem yang dapat melakukan deteksi dengan cepat. Adapun bahasa pemrograman yang dipergunakan untuk membangun sistem yaitu bahasa pemrograman berbasis web dalam hal ini PHP.

\section{METODE PENELITIAN}

Adapun alur tahapan penelitian yang dilakukan dapat dilihat pada gambar 1 dibawah [10] :

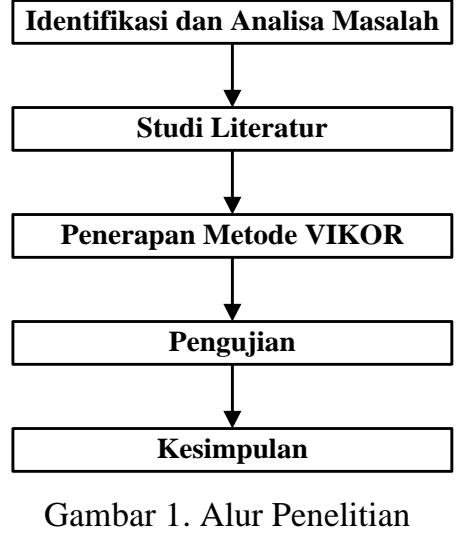

a. Identifikasi dan Analisa Masalah

Identifikasi dan analisa masalah merupakan tahapan awal dalam penelitian ini. Proses identifikasi dan analisa masalah dilakukan dengan langsung melakukan pengamatan dan wawancara ke objek penelitian. Dalam proses ini yang di wawancarai yakni wakil direktur 1 bidang akademik yang mengetahui secara jelas permasalahan mahasiswa sesuai dengan topik penelitian.

\subsection{Studi Literatur}

Studi literatur dilakukan untuk memperkuat referensi terkait topik penelitian. Adapun literatur yang dibutuhkan yakni jurnal, buku, dan literatur pendukung lainnya.

2.3 Penerapan Metode VIKOR 
Adapun penerapan metode VIKOR sebagai berikut [11] :

a) Melakukan normalisasi matriks keputusan

Normalisasi menggunakan rumus :

$$
r i j=(X j+-X i j) /(X j+-X j-)
$$

Dimana :

$\mathrm{X}_{i j}=$ Berasal dari matriks pengambilan keputusan

$\mathrm{X}_{\mathrm{J}}^{+}=$Bernilai paling baik di 1 (satu) kriteria

$\mathrm{X}_{\mathrm{J}}^{-}=$Bernilai paling buruk di 1 (satu) kriteria

b) Melakukan proses penghitungan nilai $\mathrm{S}$ dan $\mathrm{R}$

Melakukan proses penghitungan dengan menggunakan rumus :

$$
\mathrm{S}_{\mathrm{i}}=\sum_{\mathrm{j}=1}(X j+-X i j) /(+-X j-)
$$

Dimana :

$\mathrm{W} j=$ bobot kriteria

Nilai $\mathrm{S}$ diperoleh melalui proses menjumlahkan hasil perkalian bobot kriteria dengan data pada masing-masing alternatif.

$$
\mathrm{Ri}=\operatorname{Max} \mathrm{j}[\mathrm{wj}(X j+-X i j) /(X j+-X j-)]
$$

Nilai R: bernilai paling besar melalui tahapan proses perkalian bobot kriteria dengan komponen data normalisasi dari setiap alternatif.

c) Menghitung Indeks VIKOR

Menghitung Indeks dengan rumus :

$$
\mathrm{Qi}=[\mathrm{Si}-\mathrm{S}+/ S--S+] \mathrm{V}+[\mathrm{Ri}-\mathrm{R}+/ R--R+](1-\mathrm{V})
$$

Dimana :

$\mathrm{S}+=$ Memiliki nilai $\mathrm{S}$ paling kecil

$\mathrm{S}$ - = Memiliki nilai $\mathrm{S}$ paling besar

$\mathrm{R}+=$ Memiliki nilai $\mathrm{R}$ paling kecil

$\mathrm{R}-=$ Memiliki nilai $\mathrm{R}$ paling besar

Komponen nilai $\mathrm{v}$ adalah konstanta bernilai 0.5 , data alternatif bernilai $\mathrm{Q}$ yang paling kecil menjadi data alternatif yang paling baik.

\subsection{Pengujian}

Pengujian dalam penelitian ini dilakukan dengan 2 (dua) cara, yaitu cara menual dan dengan menggunakan sistem informasi yang dibangun dengan bahasa pemrograman berbasis web.

Pengujian dilakukan dengan terlebih dahulu menentukan kriteria dan bobot dari masingmasing kriteria tersebut, seperti tabel 1 dibawah :

Tabel 1 Kriteria dan Bobot

\begin{tabular}{|l|l|c|}
\hline Kode & \multicolumn{1}{|c|}{ Keterangan } & Bobot \\
\hline K1 & Lulus Mata Kuliah 80 SKS & $30 \%$ \\
\hline K2 & Lulus 7 Sertifikasi Internal & $15 \%$ \\
\hline K3 & Lulus 3 Sertifikasi BNSP & $15 \%$ \\
\hline K4 & Selesai PKL & $10 \%$ \\
\hline K5 & Lunas Uang Kuliah & $10 \%$ \\
\hline K6 & Selesai Proyek Minor & $20 \%$ \\
\hline
\end{tabular}

Berikutnya ditentukan tabel kecocokan, seperti tabel 2 dibawah : 
Tabel 2 Kecocokan

\begin{tabular}{|c|c|}
\hline Keterangan & Nilai \\
\hline Memenuhi Standar & 6 \\
\hline Belum Memenuhi Standar & 1 \\
\hline
\end{tabular}

Kemudian kumpulkan data yang akan menjadi sampel data uji. Sampel data uji dalam penelitian ini disebut dengan alternatif. Adapun bentuk datanya seperti tabel 3 berikut :

Tabel 3 Sampel Data Alternatif

\begin{tabular}{|c|c|l|l|}
\hline No & NPM & Nama & Program Studi \\
\hline 1 & 2016010005 & Amalia Nindya Pratiwi & Akuntansi \\
\hline 2 & 2016030007 & Desi Ramadhani & Manajemen Informatika \\
\hline 3 & 2016040019 & Ermita Aulia Bustami & Sekretaris \\
\hline 4 & 2016020021 & Indah Irmana & Pemasaran \\
\hline 5 & 2016050022 & Rendi Irawan & Komputerisasi Akuntansi \\
\hline
\end{tabular}

\subsection{Kesimpulan}

Kesimpulan yang dimaksud dalam penelitian ini yaitu bagaimana metode VIKOR dapat digunakan untuk menyelesaikan permasalahan sesuai dengan penelitian yang dilakukan. Kesimpulan dapat berupa hasil perhitungan secara manual maupun dengan sistem.

\section{HASIL DAN PEMBAHASAN}

\subsection{Hasil Implementasi}

Berdasarkan kriteria, kemudian bobot kriteria, kecocokan dan ketersediaan data sampel alternatif, dilakukan pengisian pembobotan alternatif untuk masing-masing kriteria. Adapun pengisiannya seperti tabel 4 berikut :

Tabel 4 Sampel Data Alternatif

\begin{tabular}{|c|c|c|c|c|c|c|}
\hline \multirow{2}{*}{ Alternatif } & \multicolumn{7}{|c|}{ Kriteria } \\
\cline { 2 - 7 } & $\mathbf{K 1}$ & $\mathbf{K 2}$ & $\mathbf{K 3}$ & $\mathbf{K 4}$ & $\mathbf{K 5}$ & $\mathbf{K 6}$ \\
\hline $\mathbf{A 1}$ & 6 & 1 & 1 & 6 & 6 & 6 \\
\hline $\mathbf{A 2}$ & 1 & 6 & 1 & 1 & 6 & 6 \\
\hline $\mathbf{A 3}$ & 6 & 1 & 6 & 6 & 6 & 1 \\
\hline $\mathbf{A 4}$ & 1 & 6 & 1 & 1 & 1 & 6 \\
\hline $\mathbf{A 5}$ & 6 & 1 & 6 & 6 & 6 & 1 \\
\hline $\mathbf{m a x}$ & 6 & 6 & 6 & 6 & 6 & 6 \\
\hline $\mathbf{m i n}$ & 1 & 1 & 1 & 1 & 1 & 1 \\
\hline $\mathbf{w}$ & $30 \%$ & $15 \%$ & $15 \%$ & $10 \%$ & $10 \%$ & $20 \%$ \\
\hline
\end{tabular}

Dari pembobotan di tabel 4, maka didapatkan hasil matrik kesimpulan sebagai berikut :

$$
\left[\begin{array}{llllll}
6 & 1 & 1 & 6 & 6 & 6 \\
1 & 6 & 1 & 1 & 6 & 6 \\
6 & 1 & 6 & 6 & 6 & 1 \\
1 & 6 & 1 & 1 & 1 & 6 \\
6 & 1 & 6 & 6 & 6 & 1
\end{array}\right]
$$

Proses berikutnya yaitu melakukan normalisasi $\mathrm{N}_{\mathrm{ij}}$ untuk semua alternatif pada masingmasing kriteria, sehingga di peroleh hasil sebagai berikut :

Tabel 5 Sampel Data Alternatif

\begin{tabular}{|c|c|c|c|c|c|c|}
\hline \multirow{2}{*}{ Alternatif } & $\mathbf{6}$ Kriteria \\
\cline { 2 - 7 } & $\mathbf{K 1}$ & $\mathbf{K 2}$ & $\mathbf{K 3}$ & $\mathbf{K 4}$ & $\mathbf{K 5}$ & $\mathbf{K 6}$ \\
\hline $\mathbf{A} 1$ & $(6-6) /(6-1)$ & $(6-1) /(6-1)$ & $(6-1) /(6-1)$ & $(6-6) /(6-1)$ & $(6-6) /(6-1)$ & $(6-6) /(6-1)$ \\
& $=0$ & $=1$ & $=1$ & $=0$ & 0 \\
\hline $\mathbf{A 2}$ & $(6-1) /(6-1)$ & $(6-6) /(6-1)$ & $(6-1) /(6-1)$ & $(6-1) /(6-1)$ & $(6-6) /(6-1)$ & $(6-6) /(6-1)$ \\
& $=1$ & $=0$ & $=1$ & $=1$ & $=0$ & $=0$ \\
\hline $\mathbf{A 3}$ & $(6-6) /(6-1)$ & $(6-1) /(6-1)$ & $(6-6) /(6-1)$ & $(6-6) /(6-1)$ & $(6-6) /(6-1)$ & $(6-1) /(6-1)$ \\
\hline
\end{tabular}




\begin{tabular}{|c|c|c|c|c|c|c|}
\hline & $=0$ & $=1$ & $=0$ & $=0$ & $=0$ & $=1$ \\
\hline $\mathbf{A 4}$ & $(6-1) /(6-1)$ & $(6-6) /(6-1)$ & $(6-1) /(6-1)$ & $(6-1) /(6-1)$ & $(6-1) /(6-1)$ & $(6-6) /(6-1)$ \\
& $=1$ & $=0$ & $=1$ & $=1$ & $=1$ & $=0$ \\
\hline $\mathbf{A 5}$ & $(6-6) /(6-1)$ & $(6-1) /(6-1)$ & $(6-6) /(6-1)$ & $(6-6) /(6-1)$ & $(6-6) /(6-1)$ & $(6-1) /(6-1)$ \\
& $=0$ & $=1$ & $=0$ & $=0$ & $=0$ & $=1$ \\
\hline
\end{tabular}

Tahapan berikutnya yakni matriks keputusan yang telah di normalisasi $(\mathrm{N})$ di kalikan dengan bobot kriteria, di dapatkan hasil normalisasi terbobot sebagai berikut :

Tabel 6 Hasil Normalisasi Terbobot

\begin{tabular}{|c|c|c|c|c|c|c|}
\hline \multirow[t]{2}{*}{ Alternatif } & \multicolumn{6}{|c|}{ Kriteria } \\
\hline & K1 & K2 & K3 & K4 & K5 & K6 \\
\hline A1 & $\begin{array}{c}0 \times 30 \% \\
=0\end{array}$ & $\begin{array}{c}1 \times 15 \% \\
=0.15\end{array}$ & $\begin{array}{c}1 \times 15 \% \\
=0.15\end{array}$ & $\begin{array}{c}0 \times 10 \% \\
=0\end{array}$ & $\begin{array}{c}0 \times 10 \% \\
=0\end{array}$ & $\begin{array}{c}0 \times 20 \% \\
=0\end{array}$ \\
\hline A2 & $\begin{array}{c}1 \times 30 \% \\
=0.3\end{array}$ & $\begin{array}{c}0 \times 15 \% \\
=0\end{array}$ & $\begin{array}{c}1 \times 15 \% \\
=0.15\end{array}$ & $\begin{array}{c}1 \times 10 \% \\
=0.1\end{array}$ & $\begin{array}{c}0 \times 10 \% \\
=0\end{array}$ & $\begin{array}{c}0 \times 20 \% \\
=0\end{array}$ \\
\hline $\mathbf{A 3}$ & $\begin{array}{c}0 \times 30 \% \\
=0\end{array}$ & $\begin{array}{c}1 \times 15 \% \\
=0.15\end{array}$ & $\begin{array}{c}0 \times 15 \% \\
=0\end{array}$ & $\begin{array}{c}0 \times 10 \% \\
=0\end{array}$ & $\begin{array}{c}0 \times 10 \% \\
=0\end{array}$ & $\begin{array}{c}1 \times 20 \% \\
=0.2\end{array}$ \\
\hline A4 & $\begin{array}{c}1 \times 30 \% \\
=0.3\end{array}$ & $\begin{array}{c}0 \times 15 \% \\
=0\end{array}$ & $\begin{array}{c}1 \times 15 \% \\
=0.15\end{array}$ & $\begin{array}{c}1 \times 10 \% \\
=0.1\end{array}$ & $\begin{array}{c}1 \times 10 \% \\
=0.1\end{array}$ & $\begin{array}{c}0 \times 20 \% \\
=0\end{array}$ \\
\hline A5 & $\begin{array}{c}0 \times 30 \% \\
=0\end{array}$ & $\begin{array}{c}1 \times 15 \% \\
=0.15\end{array}$ & $\begin{array}{c}0 \times 15 \% \\
=0\end{array}$ & $\begin{array}{c}0 \times 10 \% \\
=0\end{array}$ & $\begin{array}{c}0 \times 10 \% \\
=0\end{array}$ & $\begin{array}{c}1 \times 20 \% \\
=0.2\end{array}$ \\
\hline
\end{tabular}

Tahapan langkah berikutnya yaitu melakukan penghitungan utility measure berdasarkan alternatif. Terdapat 2 (dua) utility measure, yakni nilai S dan R sebagai berikut :

$$
\begin{aligned}
& \mathrm{R} 1=\max (0 ; 0.15 ; 0.15 ; 0 ; 0 ; 0)=0.15 \\
& \mathrm{~S} 1=0+0.15+0.15+0+0+0=0.3 \\
& \mathrm{R} 2=\max (0.3 ; 0 ; 0.15 ; 0.1 ; 0 ; 0)=0.3 \\
& \mathrm{~S} 2=0.3+0+0.15+0.1+0+0=0.55 \\
& \mathrm{R} 3=\max (0 ; 0.15 ; 0 ; 0 ; 0 ; 0.2)=0.2 \\
& \text { S3 }=0+0.15+0+0+0+0.2=0.35 \\
& \text { R4 }=\max (0.3 ; 0 ; 0.15 ; 0.1 ; 0.1 ; 0)=0.3 \\
& \text { S4 }=0.3+0+0.15+0.1+0.1+0=0.65 \\
& \text { R5 }=\max (0 ; 0.15 ; 0 ; 0 ; 0 ; 0.2)=0.2 \\
& \text { S5 }=0+0.15+0+0+0+0.2=0.35
\end{aligned}
$$

Dari Perhitungan di atas, maka akan di dapatkan nilai S, sebagai berikut :

Tabel 7 Hasil Nilai S

\begin{tabular}{|c|}
\hline Nilai $\mathbf{S}$ \\
\hline 0.3 \\
\hline 0.55 \\
\hline 0.35 \\
\hline 0.65 \\
\hline
\end{tabular}

Sementara nilai R, maka akan di dapatkan nilai sebagai berikut :

Tabel 8 Hasil Nilai $R$

\begin{tabular}{|c|}
\hline Nilai R \\
\hline 0.15 \\
\hline 0.3 \\
\hline 0.2 \\
\hline 0.3 \\
\hline
\end{tabular}


Langkah selanjutnya adalah Menghitung indeks VIKOR dengan veto $=0.5$ : $(0.3-0.65) /(0.65-0.3) \times 0.5+(0.15-0.3) /(0.3-0.15) \times 1-0.5$ $=-1$

$(0.55-0.65) /(0.65-0.3) \times 0.5+(0.3-0.3) /(0.3-0.15) \times 1-0.5$ $=-0.143$

$(0.35-0.65) /(0.65-0.3) \times 0.5+(0.2-0.3) /(0.3-0.15) \times 1-0.5$ $=-0.762$

$(0.65-0.65) /(0.65-0.3) \times 0.5+(0.3-0.3) /(0.3-0.15) \times 1-0.5$

$=0$

$(0.35-0.65) /(0.65-0.3) \times 0.5+(0.2-0.3) /(0.3-0.15) \times 1-0.5$ $=-0.762$

Maka di peroleh hasil indeks VIKOR sebagai berikut :

Tabel 9 Hasil Nilai R

\begin{tabular}{|l|l|l|}
\hline Kode & Nama Alternatif & Nilai Indeks \\
\hline A1 & Amalia Nindya Pratiwi & -1 \\
\hline A2 & Desi Ramadhani & -0.143 \\
\hline A3 & Ermita Aulia Bustami & -0.762 \\
\hline A4 & Indah Irmana & 0 \\
\hline A5 & Rendi Irawan & -0.762 \\
\hline
\end{tabular}

Setelah memperoleh nilai indeks, maka kita dapat melakukan perangkingan dengan melihat nilai yang terkecil hingga nilai yang terbesar, dimana nilai yang paling kecil adalah yang paling baik atau efektif, maka hasilnya :

Tabel 9 Hasil Nilai R

\begin{tabular}{|c|l|c|c|}
\hline Kode & Nama & Nilai Indeks & Rangking \\
\hline A1. & Amalia Nindya Pratiwi. & -1. & 1 \\
\hline A3. & Ermita Aulia Bustami. & -0.762. & 2 \\
\hline A5. & Rendi Irawan. & -0.762. & 3 \\
\hline A2. & Desi Ramadhani. & -0.143. & 4 \\
\hline A4. & Indah Irmana. & 0. & 5 \\
\hline
\end{tabular}

Berikutnya untuk tampilan dengan menggunakan aplikasi yang dibangun dengan menggunakan bahasa pemrograman berbasis web, sebagai berikut :

a) Tampilan Menu Kriteria

Tampilan menu kriteria menampilkan kriteria yang dipergunakan. Di setiap kriteria ditampilkan pula bobot dari masing-masing kriteria. Tampilan kriteria dapat dilihat pada gambar 2 berikut : 

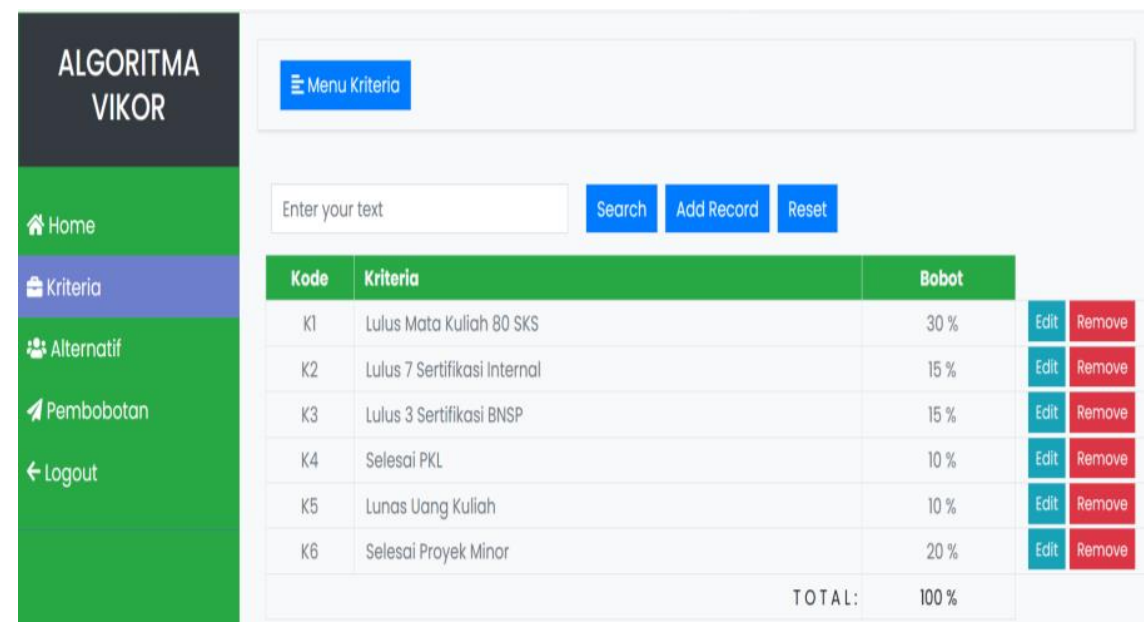

\section{Gambar 2. Tampilan Menu Kriteria}

b) Tampilan Menu Alternatif

Tampilan menu alternatif menampilkan alternatif sampel data mahasiswa yang dijadikan sebagai bahan uji coba. Adapun tampilannya dapat dilihat pada gambar 3 dibawah :

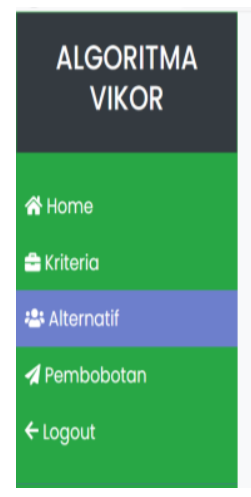

\section{EMenu Alternatif}

\begin{tabular}{|c|c|c|c|c|c|c|}
\hline \multicolumn{3}{|c|}{ Enter your text } & Add Record & Reset & & \\
\hline Kode & NPM & Nama & Telepon & Program Studi & & \\
\hline Al & 2016010005 & Amalia Nindya Pratiwi & 081387228720 & Akuntansi & Edat | & Remove \\
\hline$A_{2}$ & 2016030007 & Desi Ramadhani & 081298127781 & Mangjemen Informatika & Edit | & Remove \\
\hline A3 & 2016040019 & Ermita Aulia Bustami & 085287128889 & Sekretaris & Edit | & Remove \\
\hline A4 & 2016020021 & Indah IImana & 081989120091 & Pemasaran & Edit | & Remove \\
\hline A5 & 2016050022 & Rendi Irowan & 085789010912 & Komputerisasi Akuntansi & Edit & Rem. \\
\hline
\end{tabular}

Gambar 3. Tampilan Menu Alternatif

c) Tampilan Menu Pembobotan

Tampilan menu pembobotan menampilkan penilaian terhadap alternatif sesuai dengan kriteria yang telah ditentukan. Adapun tampilannya dapat dilihat pada gambar 4 dibawah :

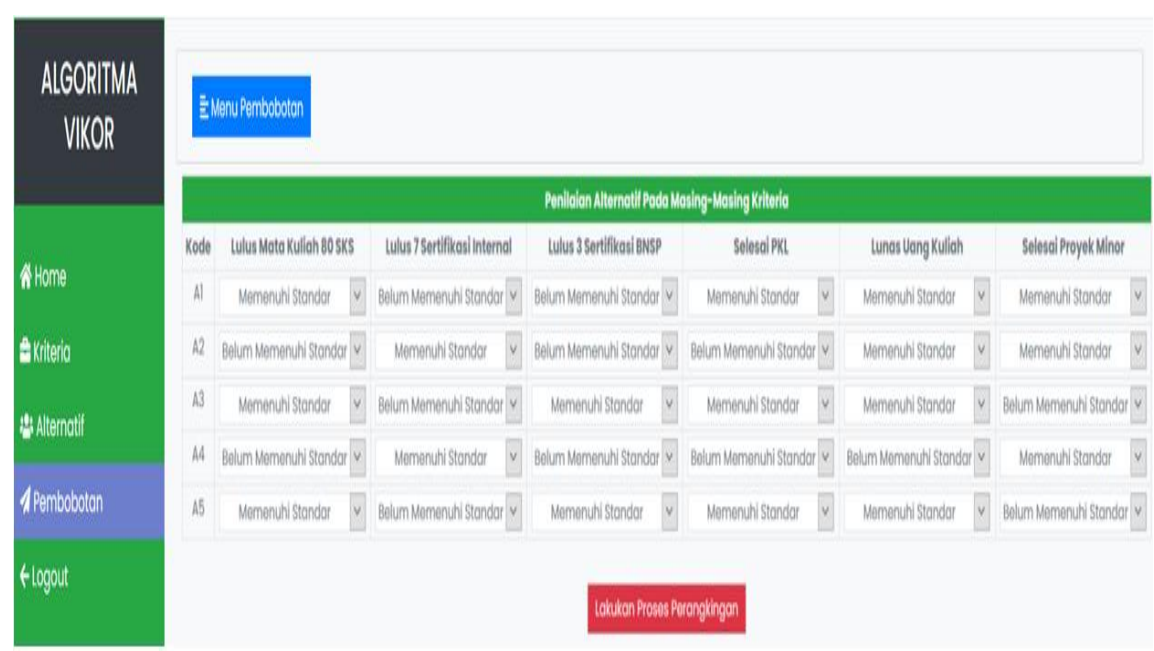

Gambar 4. Tampilan Menu Pembobotan 
d) Tampilan Menu Perangkingan

Tampilan menu perangkaningan menampilkan hasil akhir dari pengolahan data alternatif sesuai dengan kriteria yang telah ditetapkan. Adapun tampilannya seperti pada gambar 5 dibawah :

\begin{tabular}{|c|c|c|c|c|c|}
\hline \multicolumn{6}{|c|}{ Perangkingan } \\
\hline Kode & NPM & Nama & Program Studi & Nilai Indeks & Rangking \\
\hline Al & 2016010005 & Amalia Nindya Pratiwi. & Akuntansi. & -1. & 1 \\
\hline A3 & 2016040019 & Ermita Aulia Bustami. & Sekretaris. & -0.762 & 2 \\
\hline A5 & 2016050022 & Rendi Irawan. & Komputerisasi Akuntansi. & -0.762 & 3 \\
\hline $\mathrm{A} 2$ & 2016030007 & Desi Ramadhani. & Manajemen Informatika. & -0.143 & 4 \\
\hline A4 & 2016020021 & Indah Irmana. & Pemasaran. & 0. & 5 \\
\hline
\end{tabular}

Gambar 5. Tampilan Menu Perangkingan

Setelah melalui proses penyelesaian sesuai dengan ketentuan langkah-langkah metode VIKOR, maka alternatif A1 (Amalia Nindya Pratiwi) merupakan data sampel yang memenuhi syarat untuk melakukan penyusunan Tugas Akhir, sementara alternative data sampel yang lain harus memenuhi syarat terlebih dahulu agar dapat melakukan penyusunan Tugas Akhir.

\subsection{Analisa Hasil Pengujian Sistem}

Analisa hasil pengujian sistem yang telah dibangun dilakukan untuk mendapatkan dan mengetahui tingkat ketercapaian manfaat dari sistem yang telah dibangun. Sehingga dapat dilihat tingkat keberhasilan dari sistem yang telah dibangun apakah telah sesuai dengan target dan sasaran.

Pengujian terhadap sistem yang dibangun dilakukan kepada 32 orang mahasiswa. Mahasiswa diinstruksikan untuk menjalankan dan berinteraksi dengan sistem yang telah dibangun. Tujuannya agar dapat diketahui apakah sistem yang telah dibangun dapat mengakomodir kebutuhan pengguna sesuai dengan apa yang telah ditetapkan dan direncanakan. Pengujian dilaksanakan pada penggunaan tahapan-tahapan sesuai dengan penyelesaian Metode Vikor. Gabungan hasil pengujian dapat dilihat pada tabel 10 dibawah :

Tabel 10 Hasil Pengujian Sistem

\begin{tabular}{|c|l|c|c|c|}
\hline No & Aspek & Rata-rata & Nilai Kriteria Kelayakan Per Aspek & Kategori Kelayakan \\
\hline 1. & Tampilan & $4,05$. & 40,56 & Layak \\
\hline 2. & Urutan Penggunaan & $4,26$. & 46,87 & Sangat Layak \\
\hline 3. & Kecepatan Proses & $4,28$. & 51,46 & Sangat Layak \\
\hline 4. & Kesesuaian Hasil & $4,04$. & 48,5 & Layak \\
\hline \multicolumn{2}{|l|}{ Rata-rata Nilai Keseluuhan Aspek } & $\mathbf{1 8 7 , 4 0}$ & Layak \\
\hline
\end{tabular}

Korelasi hasil pengujian dengan kategori kelayakan diperoleh melalui komentar yang dipilih oleh mahasiswa pada form isian yang telah disediakan. Adapun keterangan kelayakan yang dimaksud seperti pada tabel 11 :

Tabel 11 Korelasi Kategori Kelayakan

\begin{tabular}{|c|c|c|}
\hline No & Penilaian & Keterangan \\
\hline 1. & Bobot 1 & Sangat Tidak Layak \\
\hline 2. & Bobot 2 & Tidak Layak \\
\hline 3. & Bobot 3 & Cukup Layak \\
\hline 4. & Bobot 4 & Layak \\
\hline 5. & Bobot 5 & Sangat Layak \\
\hline
\end{tabular}

Kemudian konversi kategori kelayakan memiliki pedoman yang berasal dari hasil penilaian mahasiswa terhadap sistem yang dibangun. Pedoman yang dipergunakan sesuai 
dengan respon mahasiswa sejumlah 32 mahasiswa dengan pertanyaan berjumlah 45 sesuai dengan Empat aspek yang terdapat di tabel 10. Adapun yang menjadi pedoman konversi dari kategori kelayakan sesuai dengan tanggapan dan penilaian mahasiswa akan sistem yang telah dibangun seperti tabel 12 dibawah :

Tabel 12 Petunjuk Konversi Kategori

\begin{tabular}{|c|c|c|}
\hline \multicolumn{2}{|c|}{ Nilai Antara/Selang Antara } & Keterangan \\
\hline$x>\mathrm{X}_{\mathrm{i}}+1,80 \mathrm{Sb}_{\mathrm{i}}$ & $\mathrm{X}>189$ & Sangat Layak \\
\hline $\mathrm{X}_{\mathrm{i}}+0,60 \mathrm{SB}_{\mathrm{i}}<\mathrm{x} \leq \mathrm{X}_{\mathrm{i}}+1,80 \mathrm{SB}_{\mathrm{i}}$ & $153<\mathrm{X} \leq 189$ & Layak \\
\hline $\mathrm{X}_{\mathrm{i}}-0,60 \mathrm{SB}_{\mathrm{i}}<\mathrm{X} \leq \mathrm{X}_{\mathrm{i}}+0,60 \mathrm{SB}_{\mathrm{i}}$ & $117<\mathrm{X} \leq 153$ & Cukup Layak \\
\hline $\mathrm{X}_{\mathrm{i}}-1,80 \mathrm{SB}_{\mathrm{i}}<\mathrm{x} \leq \mathrm{X}_{\mathrm{i}}-0,60 \mathrm{SB}_{\mathrm{i}}$ & $81<\mathrm{X} \leq 177$ & Kurang Layak \\
\hline$x \leq \mathrm{X}_{\mathrm{i}}-1,80 \mathrm{SB}_{\mathrm{i}}$ & $\mathrm{X} \leq 81$ & Sangat Tidak Layak \\
\hline
\end{tabular}

Berdasarkan hasil pengujian sistem yang ditampilkan pada tabel 10, memperlihatkan bahwa hasil pengujian sistem memperoleh rata-rata value atau nilai 187,40 . Jika disesuaikan dengan tabel 12, maka nilai 187, 40 dikategorikan dalam Kategori Layak. Dengan demikian sistem yang dibangun untuk mendeteksi mahasiswa yang dapat menyusun Tugas Akhir dengan menggunakan metode VIKOR, layak untuk dipergunakan.

\section{KESIMPULAN}

Adapun kesimpulan yang dapat di ambil berdasarkan tahapan penelitian yang telah dilakukan, yaitu :

a) Tahapan-tahapan penyelesaian dengan metode VIKOR dapat dijadikan solusi untuk mendeteksi mahasiswa yang dapat melakukan penyusunan Tugas Akhir. Terlihat dari aspek kecepatan proses di rata-rata 51,46 yang merupakan kategori Sangat Layak.

b) Komponen-komponen pendukung seperti kriteria dan bobot, kecocokan kriteria, dan alternatif dengan metode VIKOR dapat memproses dengan kinerja maksimal. Sesuai dengan nilai rerata keseluruhan aspek sebesar 187,40 yang masuk kepada kategori Layak.

c) Metode VIKOR dapat dikombinasikan dengan bahasa pemrograman berbasis komputerisasi seperti bahasa pemrograman berbasis web dalam hal ini PHP.

\section{DAFTAR PUSTAKA}

[1] I. P. T. AKHIR, "Buku Panduan Tugas Akhir," BUKU Pandu. TUGAS AKHIR, p. 13, 2020.

[2] R. A. Purba et al., Aplikasi Teknologi Informasi: Teori dan Implementasi. Yayasan Kita Menulis, 2020.

[3] U. Verawardina and J. Jama, "Philosophy TVET Di Era Derupsi Revolusi Industri 4.0 Di Indonesia," J. Filsafat Indones., vol. 1, no. 3, pp. 104-111, 2018.

[4] S. Nurhalimah, T. Tampubolon, W. B. Berutu, J. Simarmata, and M. Mesran, "Sistem Pendukung Keputusan Penerimaan Beasiswa Pada AMIK STIEKOM Sumatera Utara Menggunakan Metode VIKOR," in Seminar Nasional Sains dan Teknologi Informasi (SENSASI), 2018, vol. 1, no. 1.

[5] M. Mesran, K. Ulfa, D. P. Utomo, and I. R. Nasution, "Penerapan Metode VlseKriterijumska Optimizacija I Kompromisno Resenje (VIKOR) dalam Pemilihan Air Conditioner Terbaik," Algoritm. J. ILMU Komput. DAN Inform., vol. 4, no. 1, p. 24, 2020.

[6] T. Imandasari and A. P. Windarto, "Penerapan Metode VIKOR Pada Pemilihan Popok Bayi Berdasarkan Jenis Kulit," in Seminar Nasional Sains dan Teknologi Informasi (SENSASI), 2018, vol. 1, no. 1. 
[7] S. P. Lengkong, A. E. Permanasari, and S. Fauziati, "Implementasi Metode VIKOR untuk Seleksi Penerima Beasiswa," in Proc. 7 th Natl. Conf. Inf. Technol. Electr. Eng, 2015, vol. 33, pp. 107-112.

[8] Y. Primadasa and H. Juliansa, "Penerapan Metode Vikor dalam Seleksi Penerimaan Bonus Pada Salesman Indihome," Digit. Zo. J. Teknol. Inf. Dan Komun., vol. 10, no. 1, pp. 33-43, 2019.

[9] D. Siregar et al., "Multi-Attribute Decision Making with VIKOR Method for Any Purpose Decision," in J. Phys. Conf. Ser, 2018, vol. 1019, no. 1.

[10] R. Garg, "Multi-Criteria Decision Making Approach : A Case Study of Team Leader Selection in IT Sector," vol. 4, no. 2, pp. 89-93, 2017.

[11] A. Mardani, E. K. Zavadskas, K. Govindan, A. Amat Senin, and A. Jusoh, "VIKOR technique: A systematic review of the state of the art literature on methodologies and applications," Sustainability, vol. 8, no. 1, p. 37, 2016. 